\title{
Myocardial rupture after acute myocardial infarction
}

Sir,

The interesting article on myocardial rupture by Feneley et al. (1983; 49: 550-6) clearly shows that prognosis in these cases can be improved by early surgical intervention. Although the lives of two of 12 patients with rupture of the free wall after acute myocardial infarction could thus be saved, the prognosis in these cases is much gloomier than suggested by these figures. Feneley et al. found an incidence of free wall rupture in 14 of $2581(0.5 \%)$ patients admitted with acute myocardial infarction. My experience ${ }^{1}$ shows a much higher incidence of this complication.

From 1967 to 1974, 940 patients were admitted to our coronary care unit with acute myocardial infarction (based on WHO criteria). Of these patients, 200 died, and a necropsy was performed in 191 of them. Rupture of the free wall was found in $29(3.1 \%)$ patients, rupture of the ventricular septum in five, and rupture of a papillary muscle in three. In two other studies in which a necropsy was performed in more than $90 \%$ of patients who died after myocardial infarction, ${ }^{2}{ }^{3}$ the incidence of rupture of the free wall was $8 \%$ and $5 \%$ of all patients admitted with acute myocardial infarction.

These findings strongly suggest that rupture of the free wall is much more common than is indicated by the clinical features-sudden bradycardia and circulatory collapse-alone. The prognosis is still unfavourable. In most cases death is sudden and unexpected; the formation of a false aneurysm is rare.

\section{R J A F Vroom,}

Aarle Rixtelseweg 101,

5707 GK Helmond,

The Netherlands.

\section{References}

1 Vroom RJAF. Hartbewaking in Streekziekenhuis. Amsterdam, 1977. Thesis.

2 Meurs AAH, Vos AK, Verhey JB, Gerbrandy J. Electrocardiogram during cardiac rupture by myocardial infarction. $\mathrm{Br}$ Heart $\mathcal{F}$ 1970; 32: 232-5.

$3 \mathrm{Lie} \mathrm{KI}$. Acute myocardial infarction in the coronary care unit. Amsterdam, 1974. Thesis.
This letter was shown to the authors, Dr Feneley and colleagues, who reply as follows:

Sir,

We thank Dr Vroom for his comments. We agree that the incidence of free wall rupture is higher than our figures suggest. As Dr Vroom points out, most people who develop free wall rupture die suddenly, precluding definite diagnosis before death. A true estimate of the incidence of free wall rupture, therefore, requires a $100 \%$ necropsy rate in patients dying after acute myocardial infarction. The necropsy rate $(56 \%)$ in our series was much lower than the commendably high rate $(95 \%)$ in Dr Vroom's series. Furthermore, necropsies were more commonly performed on younger patients dying after acute myocardial infarction in our coronary care unit. As free wall rupture is more common in older patients a relatively low incidence detected at hecropsy would be expected.

The comparatively high incidence of interventricular septal rupture in our series, on the other hand, reflects our role as a major referral centre for patients with complicated myocardial infarction. Transfer of such patients from smaller peripheral hospitals inflates the apparent incidence of this complication in our coronary care unit.

For these reasons, we avoided expressing our data as percentages of the total infarct population. The relative incidence of free wall rupture and septal rupture has been well dealt with by others, including Dr Vroom. The major purpose of our report was to emphasise the importance of early surgical intervention in potentially salvageable patients with myocardial rupture. Such patients are those with ventricular septal rupture and the small number of patients who are lucky enough to survive the onset of free wall rupture-namely, those with subacute heart rupture.

M P Feneley, V P Chang, M F O'Rourke, Cardiovascular Unit,

St Vincent's Hospital,

Darlinghurst,

New South Wales 2010,

Australia. 